\title{
A COMPARISON OF ROCHEM REVERSE OSMOSIS AND SPIRAL WOUND REVERSE OSMOSIS MEMBRANE MODULES (U)
}

by J. L. Siler

WSRC-RP-92-239

Westinghouse Savannah River Company

Savannah River Site

DE93 002806

Aiken, South Carolina 29808

Other Authors:

This paper was prepared in connection with work done under Contract No. DE-AC09-89SR18035 with the U. S. Department of Energy. By acceptance of this paper, the publisher and/or recipient acknowledges the U.S. Government's right to retain a nonexclusive, royalty-free license in and to any copyright covering this papel, along with the right to reproduce and to authorize others to reproduce all or part of the copyrighted paper.

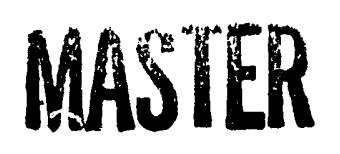




\section{DISCLAIMER}

This report was prepared as an account of work sponsored by an agency of the United States Government. Neither the United States Government nor any agency thereof, nor any of their employees, makes any warranty, express or implied, or assumes any legal liability or responsibility for the accuracy, completeness, or usefulness of any information, apparatus, product, or process disclosed, or represents that its use would not infringe privately owned rights. Reference herein to any specific commercial product, process, or service by trade name, trademark, manufacturer, or otherwise does not necessarily constitute or imply its endorsement, recommendation, or favoring by the United States Government or any agency thereof. The views and opinions of authors expressed herein do not necessarily state or reflect those of the United States Government or any agency thereof.

This report has been reproduced directly from the best available copy.

Available to DOE and DOE contractors from the Office of Scientific and Technical Information, P.O. Box 62, Oak Ridge, TN 37831; prices available from (615) 576-8401, FTS 626-8401.

Available to the public from the National Technical Information Service, U.S. Department of Commerce, 5285 Port Royal Rd, Springfield, VA 22161. 
Keywords: Membrane

Fouling, Bacteria, F/H ETF, Reverse Osmosis, RoChem, Spiral-Wound,

Water Flux, Salt Rejection, Decontamination Factor

Retention Time: Permanent

January 31, 1992

To: D. L. Fish, 773-A

From: J. I. Siler, 676-T g/S

A Comparison of Rochem Reverse Osmosis and Spiral-Wound

Reverse Osmosis Membrane Modules (U)

\section{SUMMARY}

Testing of the RCChem Disc Tube ${ }^{\circledR}$ reverse osmosis (RO) module's performance on biologically active feed waters has been completed. Both the Rochem module (using Filntec standard-rejection seawater membranes) and the Filmtec spiral-wound membrane module (using Filmtec high-rejection seawater membranes) were tested with simulant solutions containing typical bacteria and metal hydroxide levels found in the F/H Effluent Treatment Facility (ETF) influent.

The results indicate that the Rochem module gave superior performance over that of the spiral-wound module. Water flux losses were reduced by over $30 \%$ for water recoveries above $40 \%$. Salt DF loss was greatly reduced when the rochem module was used. For example, the DF loss after processing three batches of bacteria-containing feed was 0-15\% for the Rochem module as compared to 30-40\% for the spiral-wound module.

Another advantage to the Rochem module was that membrane DF performance could be restored by a single $\mathrm{NaOH}$ cleaning. This is in contrast to the two-step NaOH-then-Filmtec cleaning necessary with the spiral-wound module [Siler (1992)].

Interim Waste Teschnology (IWT) recommends that the ETF evaluate the installation of a pilot Ro unit for demonstration of the Rochem technology on actual feed waters. The laboratory unit at TNX would be ideally suited for this task. An alternate to locating the unit in the ETF would be to place the unit on the apron of an H-Area retention basin. This water would be an excellent test of the Rochem module's ability to process bacteriologically active waters. 


\section{INTRODUCTION}

ETF biofouling problems with the reverse osmosis membranes [e.g., Siler (1991a-1991c)] has been thoroughly evaluated and several potential improvements discovered. An improved method for membrane cleaning was developed [Siler (1992)]. These improvements should result in some improvement in the ETF's ability to produce the needed quality and quantity of Ro permeate. However, the need still exists for enhancement of the present system or an alternate technology to significantly improve the RO system at the ETF. This is because the possibility of high feed salt content due to certain Canyon operations would render the treated water quality unacceptable for discharge, and hence possibly result in shutdown of the operations.

Rochem Separations systems of Torrance, California has a relatively new (five years old) membrane technology based on a modified plate-and-frame design. Their Ro module can utilize any membrane vendor's flat membrane sheet which they can ultrasonically weld into a "pillow". A description of the internals of the module is shown in Figure 1. The pillows are stacked in alternating fashion with feed support plates. Pressurized feed travels over the pillows on each side through an open $(1 \mathrm{~mm})$ flow channel. The flow reverses direction each time it traverses either side of the pillow, and then travels o ito the next pillow. The permeate travels through the center of the pillows toward the certral core of the membrane module, and exits the module. The permeate stream is isolated from the feed/concentrate via 0 rings on both sides of the pillows. All connections (feed, permeate, and concentrate) are located on the same end of the module for simplicity.

There are several advantages to this type of design. The primary advantage is that the feed channel is open, and does not contain any spacer material as in the case of the spiral-wound modules. This allows the module to process much dirtier feeds, with the restriction on particle size being the $1 \mathrm{~mm}$ channel opening. This module can process feeds with 5 minute SDI (silt density index) values of 16 (tho maximum value is 20 ). Water with this value of SDI would severely foul conventional spiral-wound modules.

Another advantage of the open channel design is that biologically active feeds can readily be processed. The absence of the spacer material eliminates "dead spaces" that are available for bacteria to attach and grow in the spiral-wound module. The pillows "flori and flutter" in the feed solution being processed, which increases their resistance to fouling. Also, due to the lack of spacer material, cleaning the Rochem module should be easier.

Another attractive feature of the Rochem module is that only the membrane pillows would need to be disposed of when membrane replacement was necessary. This would result in a minimization of the waste volume generated over disposal of the Filmtec modules in use todày. 
The main disadvantage to the Rochem design is that the membrane packing density is significantly less. A standard Rochem module is 8" in diameter and 40 " long, with about $75 \mathrm{ft}^{2}$ of membrane area. The Filmtec modules in use at the ETF are physically the same size, but the spiral-wound elements have $280 \mathrm{ft}^{2}$ of membrane area. Thus more Rochem modules would be required to process a given flow.

Cost is also a concern with the Rochem module. A single Rochem element will cost about $\$ 8,000$; whereas, the Filmtec elements will cost less than $\$ 2,000$. Of course, large purchases of Rochem elements would substantially reduce the cost/module. Costs could be potentially offset by increased run time between cleanings, and improved performance due to reduction of biofouling.

The reduced surface area and module cost are partially offset by the fact that the Rochem module can operate at 1,400 psi, versus 1,000 psi for the standard Filmtec module. In addition, Rochem is modifying the elements to operate at $2,100 \mathrm{psi}$, which would further offset the reduced area by allowing the modules to operate at 2-3 times the pressure that spiral-wound modules are operated. This would make the modules competitive with standard spiral-wound modules.

ROChem personnel described a landfill leachate treatment plant in Germany which used Filmtec spiral-wound modules to treat their wastewater [LaMonica (1991)]. The feed water came from an open lagoon and was biologically active. The membranes would rapidly foul and had to be replaced several times within two years. A Rochem system was installed parallel to the Filmtec system and operated continuously. The Rochem system was cleaned routinely once every 8-10 days with detergent, with complete restoration of membrane performance. The Germans elected to discontinue the use of the Filmtec syste, and use the Rochem system exclusively.

\section{EXPERIMENTAL PROCEDURE}

A series of tests were conducted to evaluate whether the Rochem module would perform better than the existing spiral-wound modules in use at the ETF. These tests involved processing solutions containing metal ( $\mathrm{Al}, \mathrm{Fe}$ ) hydroxides, Si, and salt. Tests were also done with $1 . E 7 / \mathrm{ml}$ bacteria present. Chemical cleaning of the fouled membrane was performed with a caustic wash at $35^{\circ} \mathrm{C}$, and the unit was rinsed and a standard salt test $\left(2,000 \mathrm{mg} / 1 \mathrm{NaNO}_{3}\right)$ was performed.

The basic experimental procedure was outlined in report \#WSRC-RP91-431. Detailed operating instructions can be found in TNX operating procedure \#679T90039.

A sample run cycle, along with pertinent calculations, is shown in Figure 2. The permeate is diverted to drain to simulate the 
movement of the feed solution through the membrane system. The tank is then refilled and additional reagents and bacteria (if needed) are added.

The quantity "\% water recovery" is used to allow different rates of membrane fouling to be compared properly. The flow-averaged DE is used to estimate the overall performance of the three-stage system at the ETF from single-module data.

The results obtained with the Rochem module could not be compared directly to the spiral-wound module data. This is because the Rochem module contained Filmtec standard-rejection seawater membranes, and the spiral-wound module contained a high-rejection seawater membrane. The high-rejection membrane has inherently higher DFs and lower water flux, and thus a direct comparison would be very misleading. These differences were overcome by normalizing the permeate flow and flow-averaged DFs. The normalized permeate flow is computed by dividing the value at any time by the starting flow value. The flow-averaged DFs are normalized by dividing the DFs with bacteria present by the values obtained for a bacteria-free solution.

\section{RESULTS AND DISCUSSION}

\section{Results of Processing Bacteria-Containing Feeds}

The Rochem module was evaluated on simulants with and without bacteria to determine whether this design is prone to bacterial fouling. The results are given in Figures 3 and 4 . It can be seen that approximately 5\% greater flux loss occurred after processing five bacteria batches or cycles than was observed for the bacteria-free solution. The salt DF in the presence of bacteria was about the same as in the bacteria-free solution. In fact, the DF was slightly higher when bacteria were present.

The Rochem module performed much better than the spiral-wound module on bacteria-containing solutions. It can be seen in Figure 5 that the water flux, after processing three bacteria batches, was 5-15\% higher for the Rochem module than the spiral-wound unit. Substantially higher DEs were sustained (Figure 6). Biofouling reduced the ROChem DFs by a maximum of 15\%; whereas, DFs with the spiral-wound modules were reduced up to $45 \frac{\circ}{6}$.

The lack of appreciable bacterial fouling with the Rochem module indicates superior performance to the standard spiral-wound element. This type of performance could enable the ETF membrane system to operate as designed (both in terms of water quality and quantity) by using the Rochem modules to augment the present system.

\section{Results of Cleaning the ROCHem Module}

A summary of the cleaning studies involving both the Rochem and spiral-wound modules is given in Figures 7 and 8 . It is obvious 
that the Rochem module was much easier to clean after contacting the metals and bacteria solutions. A single caustic cleaning completely restored the salt rejection, as shown in Figure 7 . This was not the case with the spiral-wound membrane, as shown in Figure 8. An approximate 30\% DF loss remained after the membrane was cleaned with NaOH. A subsequent Filmtec Alkaline Cleaner step was necessary to restore performance [Siler (1992)].

\section{CONCLUSIONS AND RECOMMENDATIONS}

The Rochem membrane module demonstrated superior performance to that observed when using a standard spiral-wound module. The membrane successfully processed a solution of bacteria and metals with minimal fouling (in terms of both flux and DF). Also, the Rochem module could be cleaned with a single $\mathrm{NaOH}$ wash, as opposed to a two-step cleaning procedure for use with the spiral-wound module.

IWT recommends that the ROchem membrane module be evaluated on actual wastewater at the ETF. This could be accomplished via installation of a pilot system at the ETF. The laboratory unit at TNX would be ideally suited for this task.

Another possibility woul' be to process water out of a retention basin in $H$ Area. The, ilot unit could be located on the apron next to the basin. The unit would simply draw water out of the basin, process it through the module, and return the permeate and concentrate to the basin. Water flux and salt DF could be monitored to study the membrane's performance on this high bioactivity water.

\section{QUALITY ASSURANCE}

The work described in this report was performed according to the guidelines in the SRS QA manual. The data collected during these tests were recorded in laboratory notebook \#WSRC-NB-90-257.

\section{REFERENCES}

Lamonica, D., Private Communication, Rochem separation systems, Torrence, California, 1991.

Rochem Separation Systems Products Brochure, Torrence, California, 1991.

Siler, J. L., "The Influence of Bacteria on Reverse Osmosis Performance at the F/H Effluent Treatment Facility - A Preliminary Investigation(U)", WSRC-RP-91-431, April 10, 1991.

Siler, J. L., "The Effect of Bacteria and Low Concentrations of Sparingly-Soluble Inorganics on Reverse Osmosis Performance at the F/H Effluent Treatment Facility(U)", WSRC-RP-91-780, August 1, 1991: 
D. I. FISH

Siler, J. I., "Remediating Biofouling of Reverse Osmosis Membranes (U) ", WSRC-RP-91-1059, October 22, 1991.

Siler, J. L., "A Comparison of Reverse Osmosis Membrane Cleaning Methods (U) ", WSRC-RP-92-56, January 27, 1992.

CC: W. L. Tamosaitis, 773A

S. T. Wach, 703H

I. K. Sullivan, 703H

D. F. Brown, $703 \mathrm{H}$

M. Goodman, 703H-ETE

P. M. Staph, 703H-ETF

A. W. Wiggins, 703H-ETF

D. J. McCabe, $676 \mathrm{~T}$

M. R. Poirier, 676T

L. L. Kilpatrick, $676 \mathrm{~T}$

SRL Records (4), 773A 


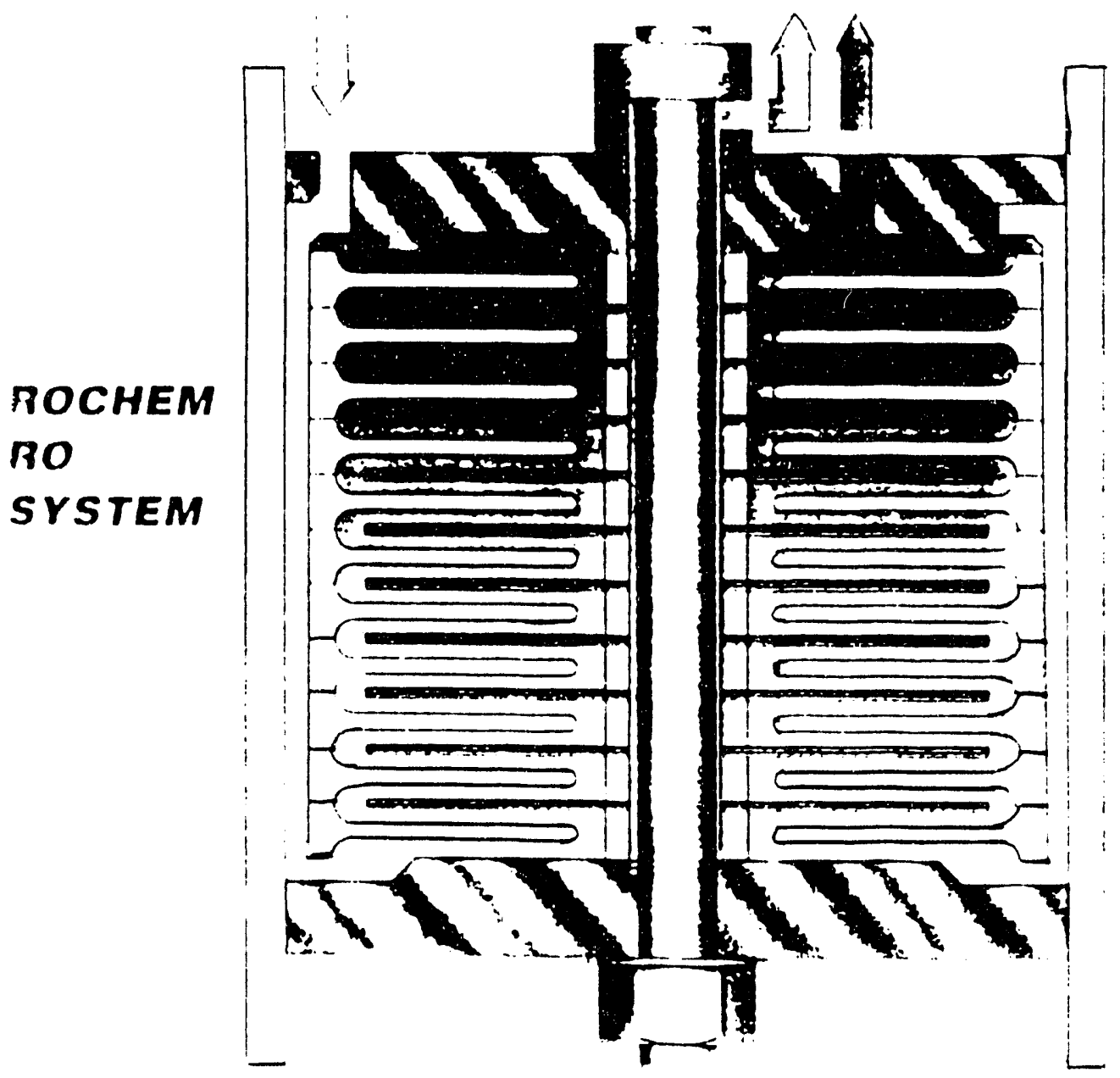

Figure 1. Diagram of the RoChem Membrane Module. [Source: RoChem Product Brochure (1991)] 
D. I. FISH

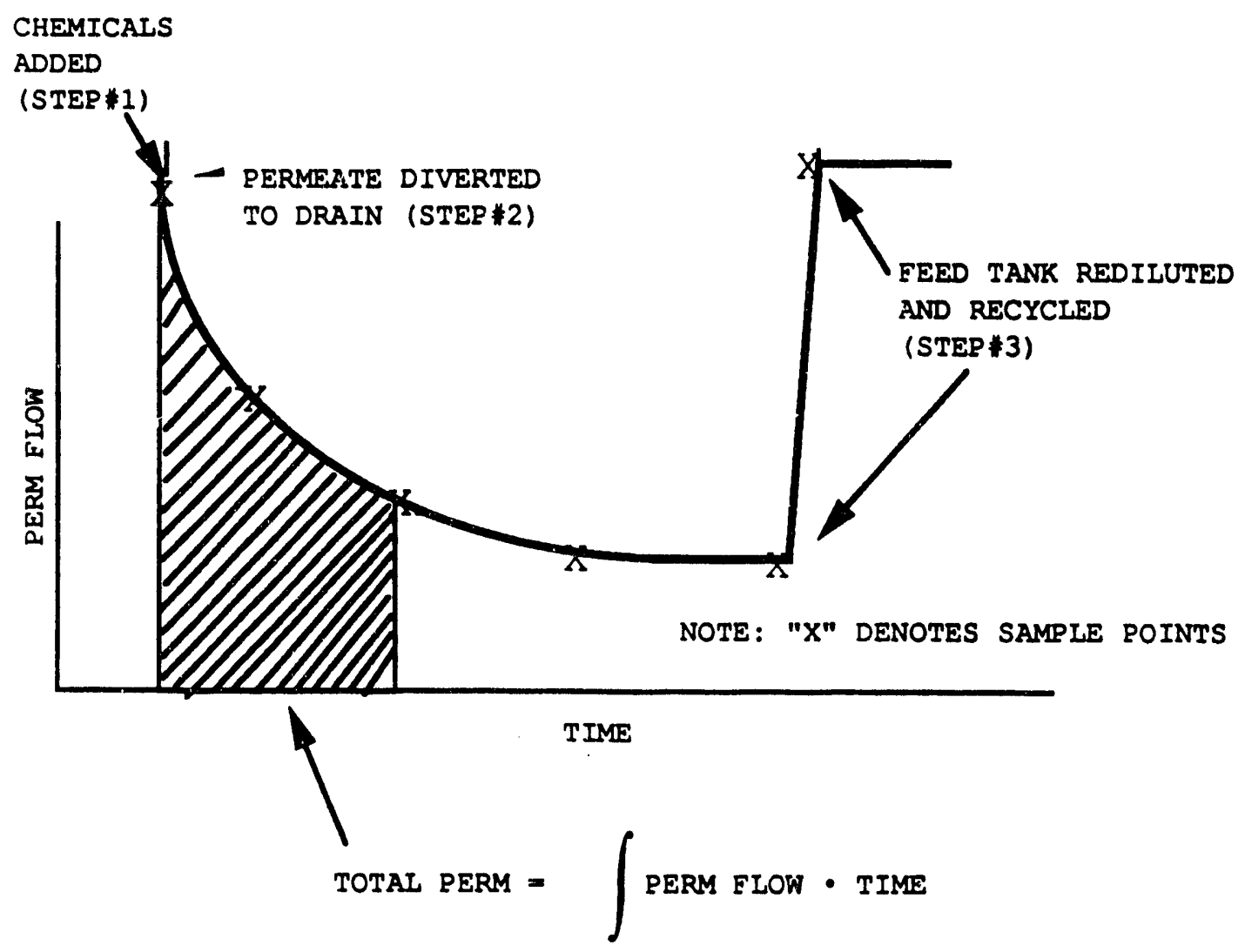

\& WATER RECOVERY $=$ TOTAL PERM/EEED VOLUME

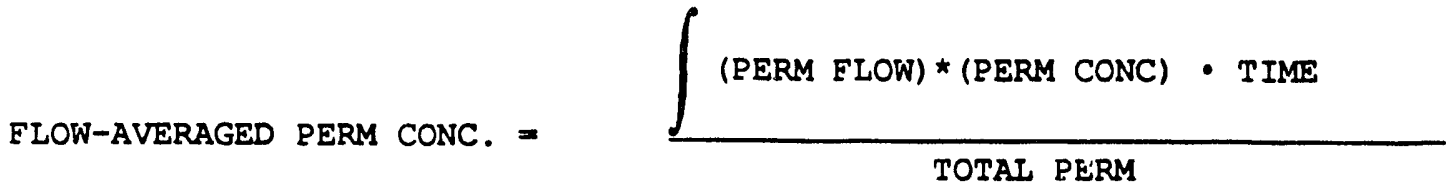

FLOW-AVERAGED DE = FEED CONC/ELOW-AVERAGED PERM CONC

Figure 2. Description of an Experimental Run Cycle and the Computation of $\%$ Water Recovery and Flow Averaged DF. 
D. I. FISH

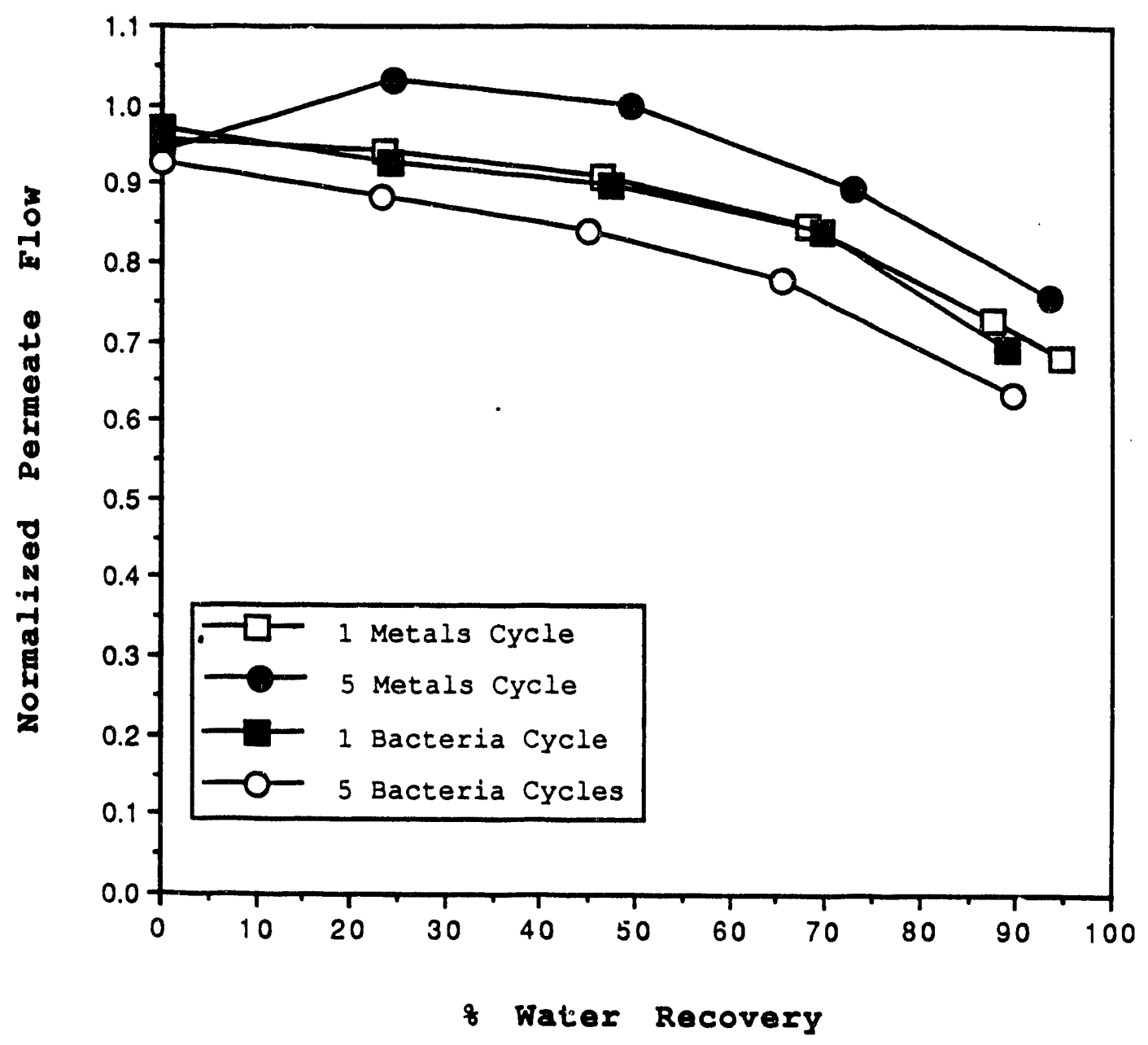

Figure 3. Comparison of KoChem Module Performance on Various Feed solutions. 
D. I. FISH

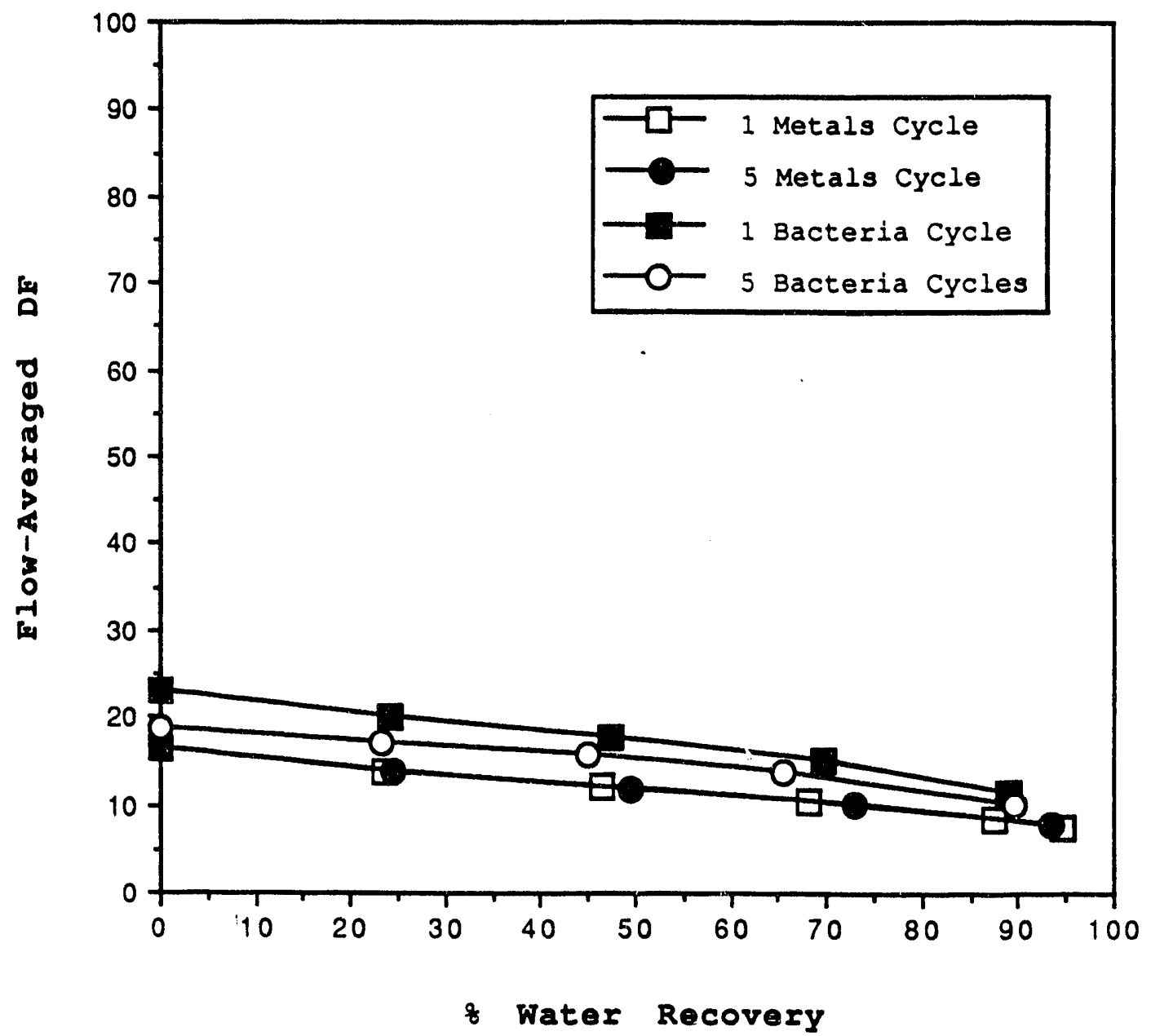

Figure 4. Comparison of salt DF for the ROChem Module on Various solutions. 


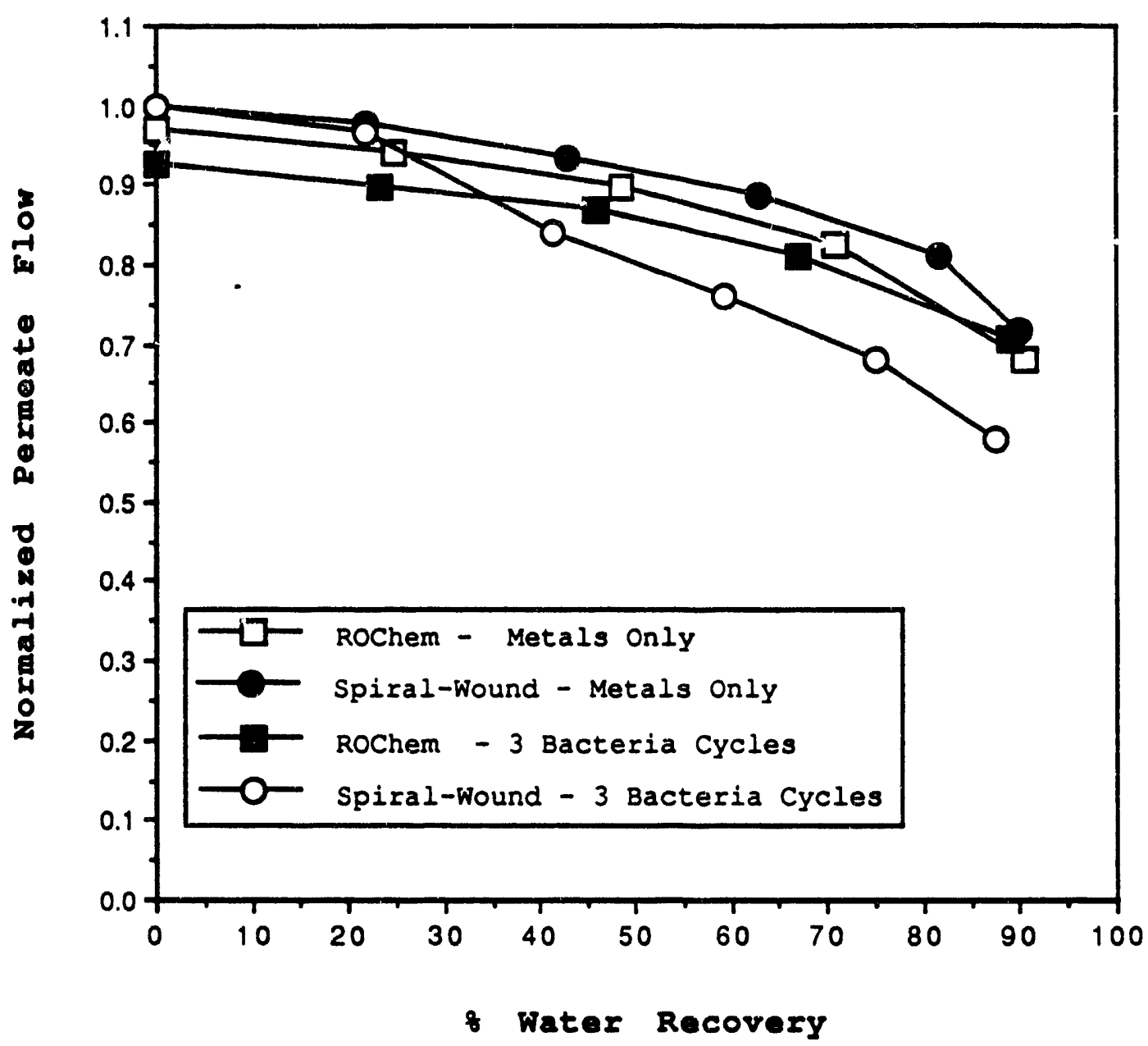

Figure 5. Water Flux Improvements Resulting From Using the ROChem Mambrane Module 

D. I. EISH

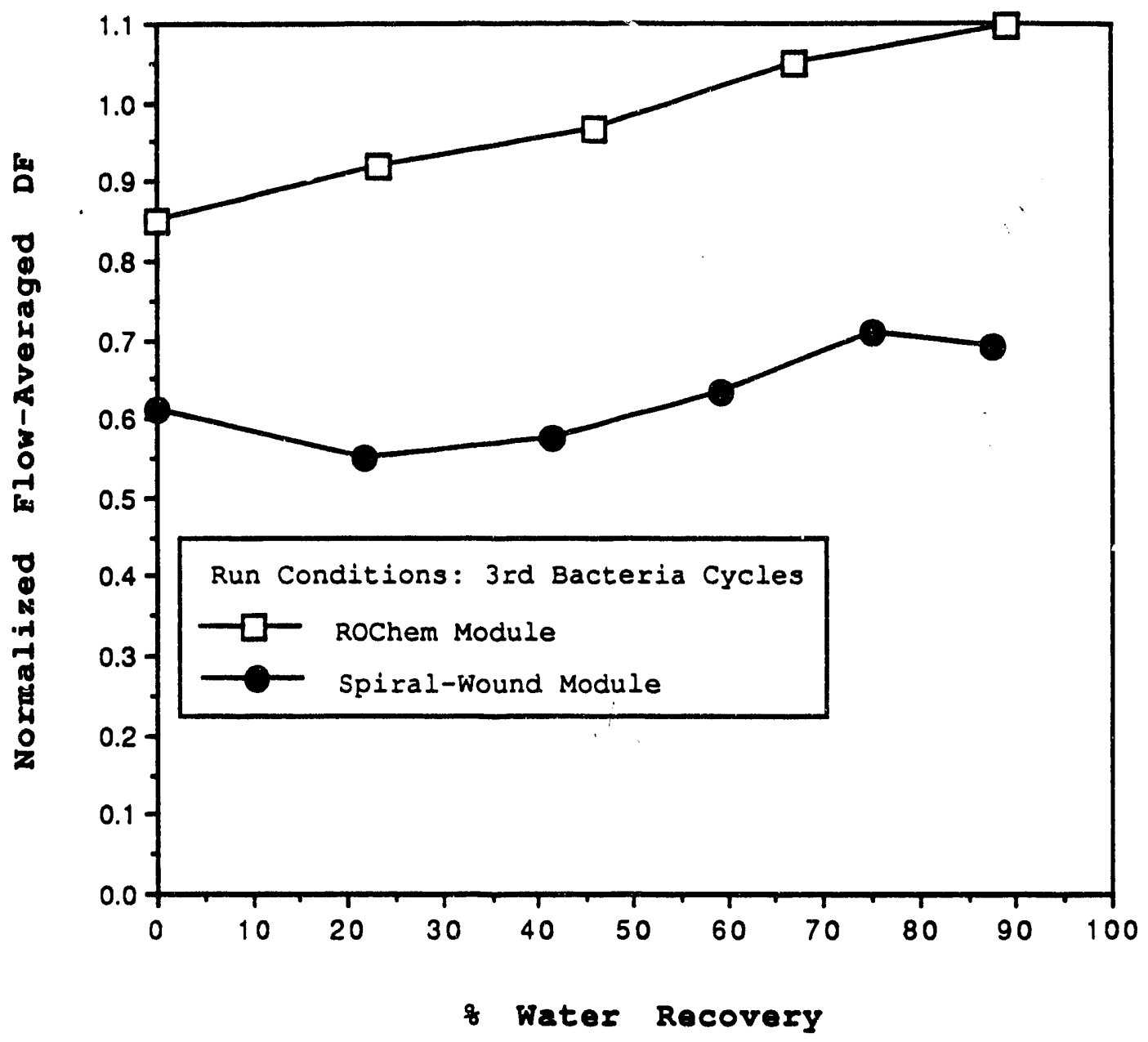

Figure 6. Improvements in salt DF from Using the ROChem Membrane Module. 


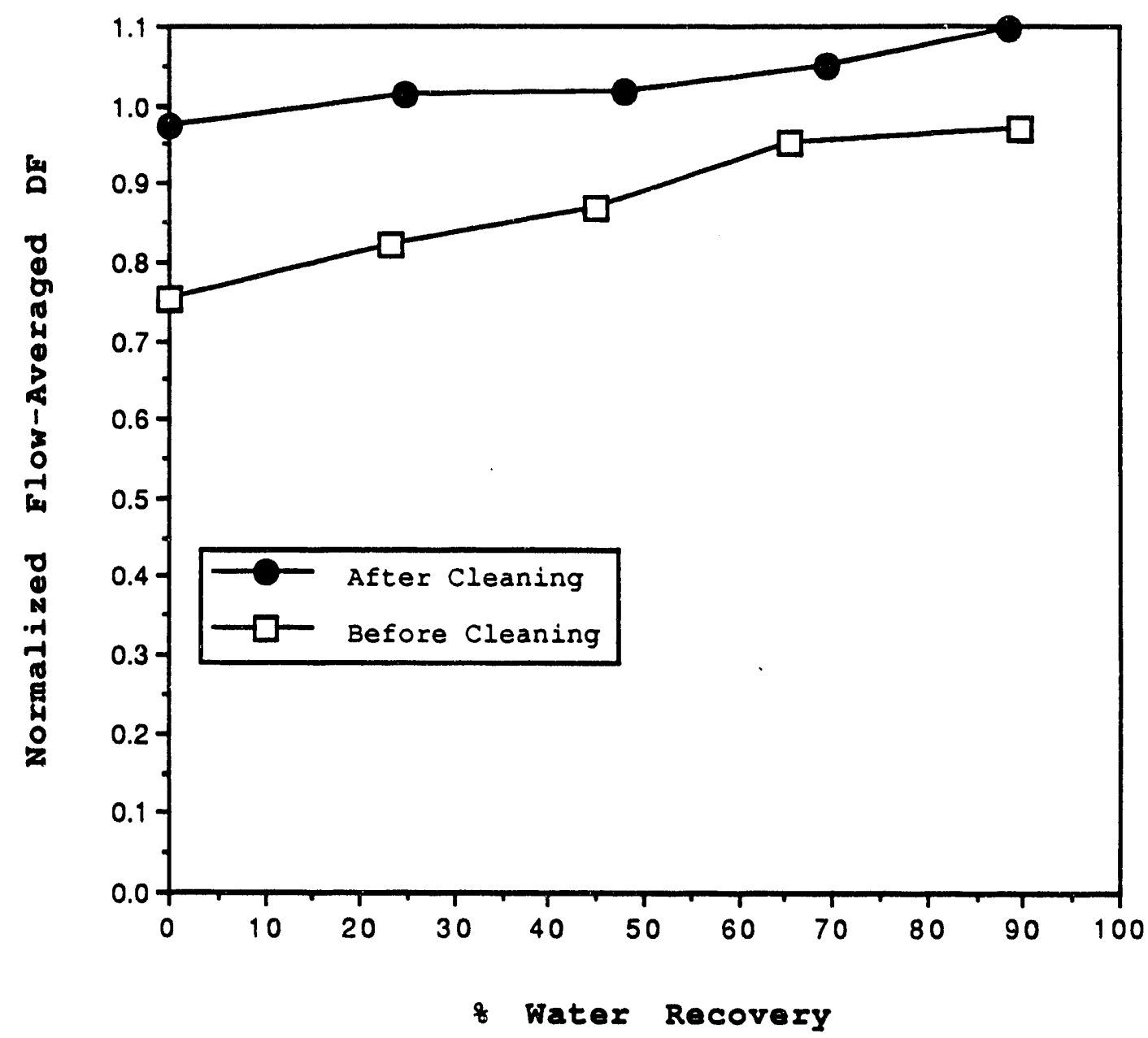

Figure 7. Effect of Caustic-Cleaning on ROChex Membrane Module Performance. 
D. I. FISH

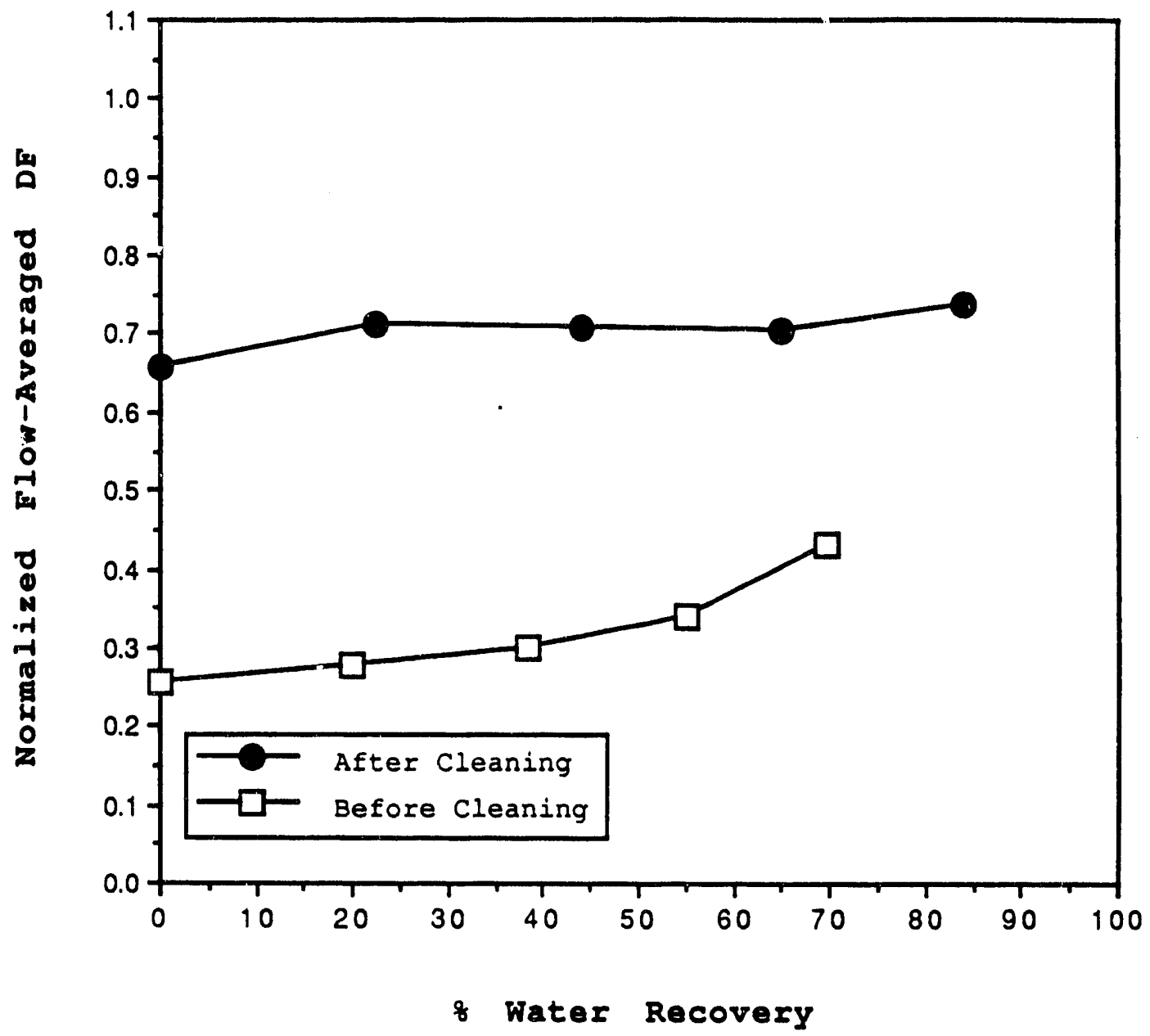

Eigure 8. Effect of Caustic-Cleaning on spiral-Found Membrane Module Performance. 

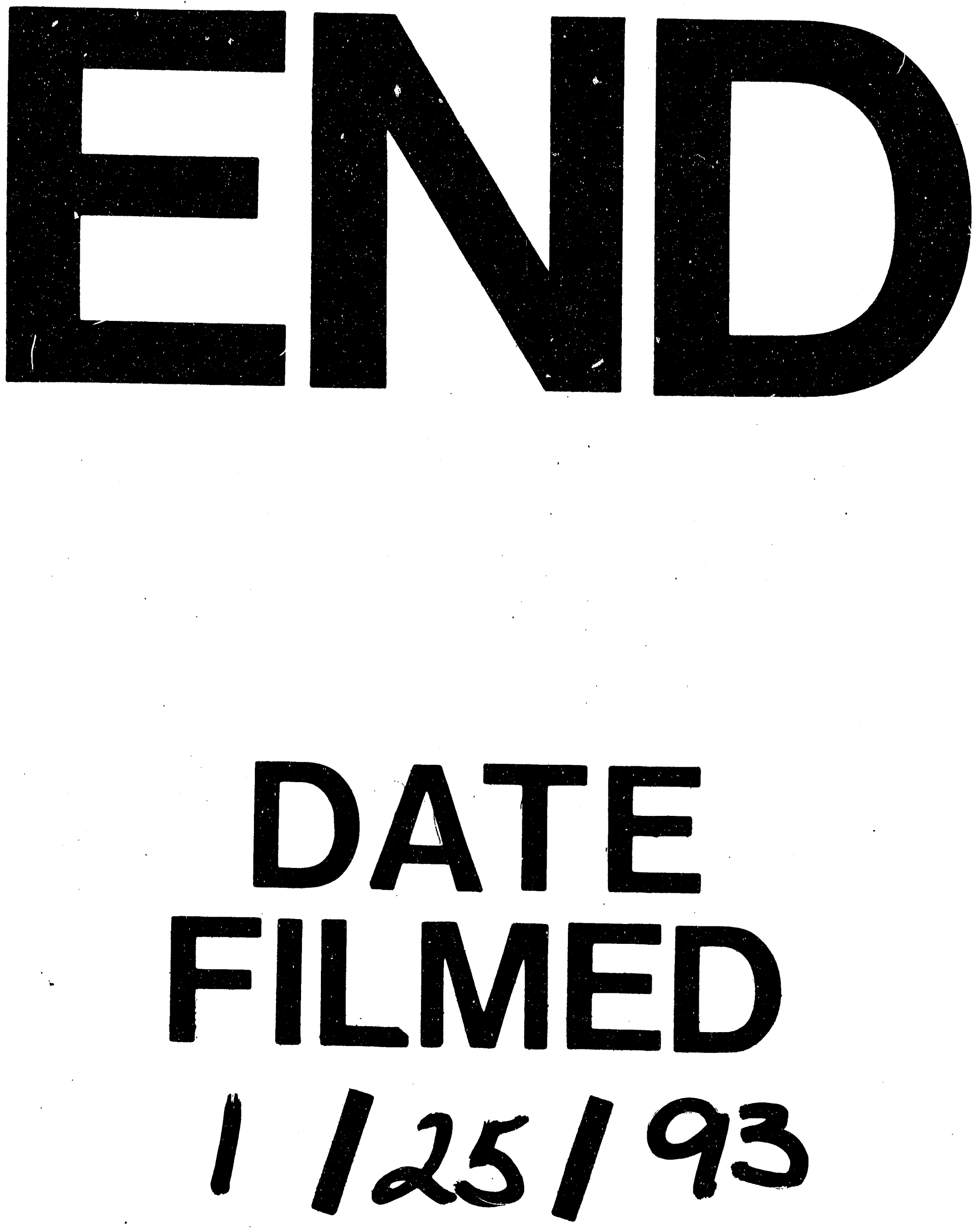
